Joshi, H.S., Jayarajan, S., Vaidyanathan, K., and Devkar, G. 2020. "Quantitative Framework for Measuring Effectiveness of Big Boom.” In: Tommelein, I.D. and Daniel, E. (eds.). Proc. $28^{\text {th }}$ Annual Conference of the International Group for Lean Construction (IGLC28), Berkeley, California, USA, doi.org/10.24928/2020/0119, online at iglc.net.

\title{
QUANTITATIVE FRAMEWORK FOR MEASURING EFFECTIVENESS OF BIG ROOM
}

\author{
Hrishikesh Sanatkumar Joshi ${ }^{1}$, Santhosh Jayarajan ${ }^{2}$, \\ Kalyan Vaidyanathan ${ }^{3}$, and Ganesh Devkar ${ }^{4}$
}

\begin{abstract}
Benefits derived from the conduct of Big Room are well established. At present, the lean practitioners have been focusing on tapping the potential of this technique by systematizing the processes associated with implementation of Big Room. But there has been no quantifiable metrics to measure the same. In this context, this paper reports a study undertaken to develop and implement Big Room Effectiveness Index (BREI) that assesses effectiveness of Big Room. This research study adopted action research approach in the context of an Indian real estate developer. A core group within this developer was formed to steer the initiative of BREI. Based on literature review and interactions within core group, 10 measures for assessing effectiveness of Big Room were identified, which are grouped under four categories: collaboration, look-ahead planning, knowledge building and tools used, and continuous improvement. The framework was codified with some flexibility to provide inputs like parameter weightages and rating of these parameters. The developed BREI was implemented in an ongoing real estate project. The BREI was plotted on a monthly basis and it provided valuable input to participants involved in the Big Room meetings and suggested areas of improvements.
\end{abstract}

\section{KEYWORDS}

Big Room/obeya, Collaboration, continuous improvement/kaizen, lookahead planning, constraint analysis.

\section{INTRODUCTION}

A construction project is a complex socio-technical system that is intertwined with an internal network of contracts and relationships, and an external network of regulations, compliances and legalities. In this microcosm, the lean philosophy inculcates the "Big Room" process to infuse an environment of collaborative and committed culture through the design-procure-construction phase of the project. There are different connotations to the term "Big Room" owing to its use across project lifecycle and benefits derived by the

1 Chief Operating Officer, Panora Infrastructure LLP, Worli, Mumbai 400018, India, hrbm1011@yahoo.com, orcid.org/0000-0001-5203-9028

2 DGM-Electrical, Tata Realty,E-Block,Voltas Compound, TB Kadam Marg, Chinchpokli,Mumbai 400033, India, santh_rfx@yahoo.com, orcid.org/0000-0002-0512-2715

3 CEO, Nadhi Information Technologies Pvt. Ltd.,\#4, Aswathi, 2nd Crescent Park Street, Gandhi Nagar, Adyar, Chennai 600020. India, kalyanv@,nadhi.in, orcid.org/0000-0001-7006-6329

4 Associate Professor, Faculty of Technology, CEPT University, Ahmedabad - 380009, India, ganesh.devkar@cept.ac.in, orcid.org/0000-0002-5482-1221 
stakeholders of the construction project. For the current study, the Big Room is conceptualized as "an on-site co-location space that physically brings together designers, builders and often facility operators to work together" (Khanzode 2020). In this colocated space, the emphasis is provided on "behaviours and actions of the team" and "collaborative behaviour and the work they are producing" (LCI 2015). Owing to popularity of Big Room, it has been discussed widely in the lean community, in aspects like purpose, design, benefits, facilitation, visual control, social network and language action (Majava et al. 2019; Priven and Sacks 2015; Viana et al. 2017). These studies often mention the need for a collective measure for assessing effectiveness of Big Room meetings. One such paper by Hill \& Fauchier (2016) discussed the idea of evaluating "team health" and performance assessment of Big Room meetings. The paper, however, fell short of mentioning steps or framework to be followed for this assessment.

The Big Room Effectiveness Index (BREI) developed as part of the current study addresses this research gap. The rest of paper is organized as follows. Section 2 discusses research methodology followed for this study. Section 3 presents the various categories to be considered to measure the effectiveness of the Big Room. Section 4 provides a quantitative framework for computing BREI. Section 5 discusses the application of the framework in the context of a project and some trends and patterns observed over a few months. Section 6 concludes with some discussion and future steps.

\section{LITERATURE REVIEW}

The literature review for this research study was conducted at the "planning stage", with reference to the action-research approach adopted and is discussed in this section.

This study began with sourcing and searching of relevant papers and documents published by Lean Construction Institute (LCI), International Group of Lean Construction (IGLC) and Institute of Lean Construction Excellence (ILCE). These papers were then grouped according to concepts, or categories or themes relevant for this study. The first set of papers focused on elements and conduct of Big Room meetings, and techniques used to maximize the effectiveness of these meetings (Hill and Fauchier 2016; Khanzode 2020; LCI 2015). Based on a review of these papers and study context, the papers were grouped into two major categories: papers discussing LPS - a lean tool practiced in the Big Room of current organization, and papers focusing on knowledge enhancement and continuous improvement. The first category included a paper by Balllard (1999) elaborating how improvement in percentage planned complete (PPC), an important measure of work flow reliability, can impact project cost and schedule. Similarly, Indian and Norwegian approaches in the use of LPS was discussed by Ravi et al (2018), in which, it was posited that lookahead planning, constraint analysis and PPC measurements in Big Room setting helps in creating ownership to the schedule and the activities. Apart from this, papers by Glenn Ballard elaborating LPS and thesis by Emmanuel Daniel on use of LPS and collaborative planning have been reviewed (Ballard et al. 2007; Daniel 2017). These papers assisted in conceptualization of two measures relating to collaboration and look-ahead planning. The second set of papers includes a paper by Salvatierra et al. (2016) that stresses on competency building for sustaining implementation of lean tools, especially LPS. Along with these competencies, the respect for people for employee engagement and support at all levels of the organization was discussed by Korb (2016), along with continuous improvement - a pillar of Toyota Production System (TPS). Tezel et al (2018) discussed the functioning of continuous improvement (CI) cells in the highway supply chain. This set of papers helped in the construction of two measures - 
knowledge building and continuous improvement. At the end of the literature review and "planning stage" of action research, the core group came up with a framework for assessing effectiveness of Big Room meetings.

\section{RESEARCH METHODOLGY}

Action research approach was adopted in this research study. The following steps were followed for action research approach: plan, act, develop and reflect (Costello 2003). The study was carried out for a real estate and infrastructure developer from India, who has more than 60 years of experience in the area. For the past few years, the developer has been adopting and refining a lean drive at all levels of management and Big Rooms in the execution phase of construction project was one such initiative. As the Big Room became a part of the project ecosystem, there was sufficient anecdotal evidence indicating the benefits of Big Room use. However, the senior management of this developer felt the need for more rigorous and systematic measurement of effectiveness of Big Room. The rationale of this measurement was that quantification of effectiveness can enable buy-ins from stakeholders involved in the construction project and systematize the use of Big Room. Along this direction, a core group was created on an ongoing construction project, that has been using big room, constituting the project in charge and planning engineer from each of the following stakeholders: client, civil contractor, project management consultant, and design firm along with a lean coach. A separate room on this construction project was provided with audio visual facility, white board, sticky notes and so on for conduct of Big Room meetings. These meetings were held on Wednesdays with participants including planner, foreman, designer, subcontractor, execution personnel etc. During the course of the Big Room, different lean tools such as last planner system, plus delta analysis and choosing by advantage were practiced, and emphasis was placed on visual representation of commitments and analyses.

The core group systematically planned, observed, implemented and reflected, in keeping with the action-research approach. First, the core group held a brain-storming session to clarify the intentions behind measuring effectiveness of the Big Room. During this session, the team felt that the process should not go overboard and "control" the environment of Big Room. Hence, the group approached an lean facilitator, to seek a third-person perspective on this drive. During the discussion with the facilitator, it became evident that the intent of measurement is not to control the environment but to bring discipline into the actions and promises in the environment of big room. It was also decided that the measure shall foster the culture of respect and integrity in Big Room meetings. After this grounding of rationale, the group held another meeting to decide the factors for measuring the effectiveness of big room. The need was felt to combine both leading parameters such as attendance to meetings and lagging parameters such as PPC. Along with this, it was ensured that these factors linked to timely completion of project. Further to this, the core group reviewed literature, as described in the earlier section, focusing on effectiveness of Big Room meetings and prepared a preliminary list of measures. There measures were workshopped and the core group arrived at a final list of measures and their respective weights. An excel template was prepared for calculating the effectiveness on a monthly basis.

Just before the implementation of this assessment, the core group met again. In this meeting, different names arose for this measure and finally it was decided to name it "Big Room Effectiveness Index (BREI)". The core team felt that further steps in this actionresearch namely observe and reflect will be useful unless two directional information 
flows are ensured, which includes information from project personnel for calculation of BREI and course correction at project site based on calculated BREI. Hence, it was decided to calculate BREI every month and report it to project stakeholders as an important measure to take stock of the health of the project.

The BREI was launched in this project on September 2018, under close monitoring and coordination by the core group. Two-way information flow was maintained. Over a period of time, the core group observed that the developed BREI had become an integral part of project progress reporting. The core group members interacted with the project stakeholders periodically to ascertain the effect of BREI in project implementation. The trend analysis of BREI was performed and discussed during the monthly project review meetings, in the presence of senior management of project stakeholders. The trend analysis and forthcoming interactions within core group as well as between core group members and other stakeholders on various forums provided an opportunity for "observing the outcomes" and "reflecting on what has happened". As part of these steps, the core group held detailed discussions and asked planning and execution personnel to narrate critical incidents that indicated improvement by adoption of BREI.

\section{EFFECTIVENESS CATEGORIES}

The first step towards development of BREI involved literature review discussing the working of Big Room meetings. As there were different lean tools being practiced on this construction project, the core group members decided to combine both generic measures focusing on conduct of Big Room and also specific measures focusing on implementation of a lean tool. With much deliberation, the team decided to include specific measures pertaining to the Last Planner System (LPS), since it has been used on this project since commencement of the execution phase. Between literature review and the deliberation of the core group, the group identified 10 measures for assessing effectiveness of Big Room Meetings. These measures were grouped under four categories: collaboration, look-ahead planning, knowledge building and tools used, and continuous improvement. The first two categories dwelled on conduct of LPS tool in these meetings while the later two led towards knowledge enhancement and continuous improvements. The core group members held a meeting to decide on weights of categories and individual measures. As the conduct of LPS in the Big Room meeting was focused upon, it was decided to assign higher weightages to these categories. Among these, the core team felt that promises made and delivered in Big Room meetings was an important component of Big Room meetings. Hence, the highest weight $(50 \%)$ was assigned to the category named collaboration. In addition to this, the Big Room meetings were expected to make the planning process collaborative and transparent, and hence, the category, look-ahead planning, was assigned $30 \%$ weight. Other two categories - knowledge building and continuous improvement were assigned $10 \%$ weight each, as it focused on leading measures that would provide benefits.

The core team realized that the weightages were assigned to skew the expectations from the Big Room meetings and that the same could be different for a different project or different scenario. Once these weightages were agreed upon, it was communicated to the team. The weightages were indicators of the importance of the category of parameters and in setting the same weightages as expectations from the team, a formulation was developed that could quantify the BREI metric for the participants of the Big Room in the execution phase of construction project. 
The formulation relies on providing relative weightage for each of the parameters and a mechanism to aggregate it to one BREI index. This led to the development of a python program that allowed end users to input the various parameters and obtain the BREI metric at the end of each Big Room meeting. Identifying the need for the metric computation to be flexible and exploratory, the authors enabled the weightages to be under the control of the end users of Big Room. To provide a controlled experiment, a brainstorming session was held with the construction execution team, and the set of relative weightages were agreed upon. These were then frozen for the duration of the application of the study. The weightages of these categories is presented in Table 1.

The users were sensitized to the idea that while spot metrics measured at the end of each meeting was relevant, what was more important was the trend of the metric time. The users were also sensitized to the larger intent behind the whole exercise. Users were told that the purpose of BREI is to learn effectiveness, look for opportunities to learn and improve while putting a quantitative framework to check for improvements in principles of lean construction like team work and collaboration. Since all Big Room meetings were also coordinated by a lean coach, care would be taken to ensure that the goal of creating a collaborative Big Room, in which, LPS is practiced effectively. This helps in efficient planning and execution of the project for attaining good BREI metrics and trends. The categories and their description are as follows:

\section{Collaboration}

The Collaboration category evaluated the commitments that are kept and the constraints that are tackled (Khanzode 2020). The very essence of the Big Room is collaboration, in which, commitments are made with or without constraints. By providing a very high weightage (50\%) to this category, the importance of collaboration is communicated to the team.

This category consists of following measures: Commitments Kept in Last Month and Constraints Tackled in Last Month. "Commitments kept" is a stakeholder's ability to give (keep) a promise, and "Constraints tackled" is a stakeholder's ability to get their constraints addressed. If the Big Room does indeed drive collaboration, then the delicate balance of give and take is optimal, which indicates true collaboration.

By keeping track of the Commitments Kept in Last Month by the various stakeholders, the reliability of the promises made by them can be evaluated. It also indicates mutual trust among stakeholders. This measure is scored from 0.00 to 1.00 based on percentage of commitments kept. The Big Room is a place of collaboration and trust building, and hence, an increase in this parameter is an indication of build-up of trust over time. It should be borne in mind that the constraints and commitments are kept in check by its interlinks to the weekly work plan and the overall phase plan. There, any buffer is within limits of reason and understanding.

The Constraints Tackled in Last Month is an indication of the cohesiveness of the team to solve problems. This measure is scored from 0.00 to 1.00 based on percentage of constraints removed. Often, the stakeholders involved in Big Room Meetings give their own commitments based on the expectation that their constraints would be removed. This mutual give and take indicates team work and commitment to the project. The tools for removal of constraints can include the application of other lean tools like value stream mapping, root cause analysis etc. as the team sees fit. 
Table 1: Sub Category and Weights

\begin{tabular}{|c|c|}
\hline Sub Category & $\begin{array}{c}\text { Weight of Sub Category } \\
\text { Score }\end{array}$ \\
\hline Collaboration & $50 \%$ \\
\hline Commitments Kept in Last Month & $50 \%$ \\
\hline Constraints Tackled in Last Month & $50 \%$ \\
\hline Look Ahead Planning & $30 \%$ \\
\hline $\begin{array}{l}\text { Variance in Number of Activities for } 6 \\
\text { Weeks }\end{array}$ & $40 \%$ \\
\hline PPC \% Achieved Last Week & $40 \%$ \\
\hline $\begin{array}{l}\text { Variance in PPC \% Achieved in Last } 6 \\
\text { Weeks }\end{array}$ & $20 \%$ \\
\hline Knowledge Building & $10 \%$ \\
\hline $\begin{array}{l}\text { Number of Training Modules } \\
\text { Conducted Last Month }\end{array}$ & $30 \%$ \\
\hline $\begin{array}{l}\text { Number of Tools Deployed/Used Last } \\
\text { Month }\end{array}$ & $70 \%$ \\
\hline Continuous Improvement & $10 \%$ \\
\hline $\begin{array}{l}\text { Number of Kaizens Received in Last } \\
\text { Month }\end{array}$ & $40 \%$ \\
\hline $\begin{array}{l}\text { Variance in Kaizens Generated in Last } \\
3 \text { Months }\end{array}$ & $20 \%$ \\
\hline $\begin{array}{l}\text { Implemented Kaizens in the Last } \\
\text { Month }\end{array}$ & $40 \%$ \\
\hline
\end{tabular}

\section{Look Ahead Planning}

Look Ahead Planning evaluates the variance in PPC scores over a period of time (Hamzeh et al. 2012). With weightage of 30 percent, it is the second category in terms of importance as identified by the core team to drive intended behaviour among the team. This category constitutes the following measures: Variance in Number of Activities for 6 Weeks, PPC \% Achieved Last Week, and Variance in the PPC\% Achieved in Last 6 weeks.

The measurement of the Variance in Number of Activities for 6 Weeks evaluates large variations in the activities planned for a week. In a mature usage of collaborative planning, it would be expected that the lookahead planning activities would not vary greatly because there will be reliability in the planning process. The Variance in Number of Activities for 6 Weeks is a measure of that. When there are big discovered activities that keep adding or getting removed, then this metric is seen as bad. On the other hand, if the activities stay largely invariant, this metric would be close to 1.00 . While, it is recognized that there is room to game the metric, it was explained to the team that the intent here is more understand the reality. If the variance is high and number of activities being added or removed is high, it is meant to be a learning opportunity to see what needs to be done to minimize variance as outlined above.

The measurement of PPC \% Achieved in Last Week give an indication of the activities that were planned and those that were completed fully. This is an indication that the 
weekly planning was effective and commitments were fulfilled as planned. This along with the previous variances in the look-ahead indicates that the reliability of the planning process is improving and that LPS is being practiced effectively.

The measurement of Variance in the PPC\% Achieved in Last 6 weeks measures changes of the PPC\% about the mean value. A high variation or a high Standard Deviation of this measure is an indication of the inconsistency in performance of actuals over planning. Consistency is good indication of a work force that is adaptive, yet productive. This metric measures the trend of the PPC from the previous metric but it specifically measures trend.

\section{KNOWLEDGE BUILDING AND TOOLS USAGE}

Knowledge Building and Tools contributes $10 \%$ weightage to the total score and assesses the provision of training to the attendees of Big Room and application of lean tools (Ballard et al. 2007; Mossman 2015). The objective of the category is to instil the idea of continuous improvement among the practitioners of lean. It includes the following measures: Number of Training Modules Conducted Last Month, and Number of Tools Deployed or Used Last Month.

Tools largely refers to the various lean tools like VSM, 5S, Work Sampling, Root Cause Analysis, 5 Why, or technology solutions relating to lean like BIM solutions, technology integrated project controls solutions etc. Eighteen Lean Tools were identified by the training team as having immediate application potential and the team was exposed to these during the course of the project.

The measure - Number of Training Modules Conducted Last Month, evaluates the number of On the Job Training (OJT) modules completed, where the Big Room is transformed into an area for sharing of ideas and concepts on Lean as well as classrooms and labs for learning and applying the concepts of lean. It also encouraged the teams to bring either external or internal trainers to Big Room meetings to showcase newer Tools (as outlined above) of lean.

The measure - Number of Tools Deployed or Used Last Month, underscores and reinforces the idea of lean being a learning environment. While some of the learning is deeper understanding of existing processes, in this case, it is learning of Tools that could help either address a concern at site or improve the overall understanding for the execution team. It helps the team apply newer tools but also look at opportunities to improve the performance of the project.

\section{CONTINUOUS IMPROVEMENT}

Continuous Improvement focuses on generation of new ideas or Kaizens for continuous improvement and implementation, and it contributes $10 \%$ of the total score weightage. It includes following measures: Number of Kaizens Received in Last Month, Variance in Kaizens in the Last 3 Months, and Implemented Kaizens in the Last Month.

The measure - Number of Kaizens in Last Month, checks for evidence of generation of Kaizen ${ }^{5}$ as a way of life among the team.

The measure - Variance in Kaizens in the Last 3 Months, checks for evidence of sustained generation of Kaizens in an effort to inculcate a culture of innovation within the team. Some of these Kaizens were simple, such as standardizing the colour of post-its for a constraint vs a commitment. Some were motivational. For example, at the request of the team, during the Big Room meeting, snacks were provided for the teams. Similarly, labor

5 A Japanese Business Philosophy based on Continuous Improvement. 
was supplied with water and tea at their workspot during cold winter months when they were working late into the evening. Still others were operational that came out of some VSM being done on a process. For example, material shifting of blocks closer to the workspot was done at night so that masons did not have to waste time waiting for materials. But all of these Kaizens came from the execution team, the last planners or the labor working onsite.

The measure - Implemented Kaizens in the Last Month checks for evidence of implementation of generated Kaizens. Quick implementation of Kaizens ensures that problems that were identified are solved while giving everyone an opportunity to contribute to the success of the project.

\section{CALCULATION OF BREI}

After arriving at the weightages of categories and specific measures, the process for calculation of BREI was automated in Microsoft Excel. The main worksheet that calculates the BREI score is shown in Figure 1. In addition, there is a second sheet that keeps track of the BREI trend and efforts for continuous improvement.

Big Room Effectiveness Index(BREI)

\begin{tabular}{|c|c|c|c|c|c|c|c|c|}
\hline SI.No & Category & Sub Category Measurable Parameter & $\begin{array}{l}\text { Sub Category } \\
\text { Weightage }\end{array}$ & $\begin{array}{c}\text { Overall } \\
\text { Weightage }\end{array}$ & $\begin{array}{c}\text { Maximum } \\
\text { Score }\end{array}$ & $\begin{array}{c}\text { Maximum } \\
\text { Weighted } \\
\text { Score }\end{array}$ & $\begin{array}{l}\text { Weighted } \\
\text { Measured } \\
\text { Score }\end{array}$ & $\begin{array}{l}\text { Improvement } \\
\text { Advice }\end{array}$ \\
\hline \multirow{2}{*}{1} & \multirow{2}{*}{ Colloboration } & Commitments Kept & 5096 & \multirow{2}{*}{$50 \%$} & 1 & 0.25 & 0.050 & Needs Attention \\
\hline & & Constraints Tackled & 5096 & & 1 & 0.25 & 0.050 & Needs Attention \\
\hline \multirow{3}{*}{2} & \multirow{3}{*}{ Look Ahead Planning } & Variance in Number of Activities per week & 4096 & \multirow{3}{*}{3096} & 1 & 0.12 & 0.10 & OKAY \\
\hline & & PPCAchieved & 4096 & & 1 & 0.12 & 0.11 & OKAY \\
\hline & & Variance in PPC Achieved & 2096 & & 1 & 0.06 & 0.02 & Needs Attention \\
\hline \multirow[b]{2}{*}{3} & \multirow{2}{*}{$\begin{array}{l}\text { Knowledge Building } \\
\text { and Tools Used }\end{array}$} & Number of Training Modules Conducted & 5096 & \multirow{2}{*}{$10 \%$} & 1 & 0.05 & 0.05 & OKAY \\
\hline & & Number of Tools deployed/Used & 5096 & & 1 & 0.05 & 0.05 & OKAY \\
\hline \multirow{10}{*}{4} & \multirow{3}{*}{ Continous Improvemer } & Number of Kaizens received in Last Month. & 4096 & \multirow{3}{*}{$10 \%$} & 1 & 0.04 & 0.02 & Needs Attention \\
\hline & & Variance in Kaizens in Last 3 Months. & \multirow{2}{*}{$\begin{array}{l}\frac{4036}{2096} \\
4096\end{array}$} & & 1 & 0.02 & 0.02 & OKAY \\
\hline & & Implemented Kaizens in Last Month & & & 1 & 0.04 & 0.02 & Needs Attention \\
\hline & & \multicolumn{2}{|l|}{ Total } & $100 \%$ & 10 & 1 & 0.48 & \\
\hline & & & & & & \multicolumn{3}{|c|}{ Overall Score Key } \\
\hline & & & & & & & Score & Verdict \\
\hline & & & & & & & 0.0 .25 & Poor Effectiveness \\
\hline & & & & & & & $0.26-0.50$ & Moderate Effectiveness \\
\hline & & & & & & & $0.51-0.75$ & Good Effectiveness \\
\hline & & & & & & & $0.76-1.00$ & Excellent Effectiveness \\
\hline
\end{tabular}

Figure 1: BREI (Big Room Effectiveness Index) Main Worksheet

In addition to calculation of the BREI index calculation for the week (spot value), the Main BREI worksheet also provides an Improvement Advice Column that identifies the sub categories that need attention. The column issues advices for scores less than $70 \%$ of the weighted score. The team is encouraged to intervene to improve the score of the category that needs attention to ensure that the scores improve without compromising on the other scores. The trend is BREI indicates that the team is improving on its adoption of collaborative practices.

\section{APPLICATION OF BREI}

The BREI model was applied on a commercial real estate project comprising of two million sq feet of floor space across two towers. The scope of work involved primarily the completion of core and shell for the two towers along with building enclosure and common area finishes. The constructed facility will be leased to large domestic and multinational clients, all of which lead to a tight deadline of project completion by March 2020 . The facility also had a tight budget as well as stringent requirements on quality and safety. The top management of client as well as the principal general contractor involved in this project provided the commitment to adopt lean practices at the enterprise level in the long 
term. As a beginning, both have agreed to use LPS and the Big Room as a contractual condition to manage project planning and deliverables. The following strategic areas were then addressed by this team to facilitate and implement pull planning with "Big Room":

- Setting up of Big Room infrastructure

- Planning, training and handholding of Big Room meetings

- Appointment of lean coach and mentors

- Creating interlinkages between critical path method (CPM) schedule and Last Planner System ${ }^{\text {TM }}$ (LPS)

- Facilitating Big Room pull planning sessions

- Monitoring progress by BREI

At the beginning of the project, the entire construction execution team involved in the project was enrolled in Big Room for pull planning and constraint identification. Further, the 6 weeks look-ahead schedule was prepared with reference to CPM schedule, for initiating discussion in Big Room meetings. The following planning approach was proposed and standardized so as to have visibility and interoperability between CPM milestone plans and look-ahead planning as done by LPS. This was to help the "Should - Can - Will - Did" approach as defined in LPS as mentioned below:

- A road map schedule (detailed at WBS Level 3) was prepared and released by Owner (the client) as "SHOULD".

- The project management consultant (PMC) managing the project on behalf of the owner would in collaboration with the Last Planners prepare the detailed construction milestones with the above schedule detailed to a "CAN" Schedule (detailed at WBS Level 4).

- In the weekly Big Room meetings, the Last Planners (who were mainly Area Managers and Foremen) would take the lead and in collaboration with the PMC extract the look-ahead activities each week from the "CAN" schedule. From these, they would highlight constraints as part of the make ready process or respond and commit to releasing a constraint as the case maybe. Constraints that could not be resolved within the lookahead window would be noted as inevitable reasons for delay.

- Last Planners then in collaboration with the PMC committed to a weekly "WILL" schedule as their commitment to project construction and completion. These were constraint-free activities from the "CAN" schedule. This was generally detailed at WBS Level 6 and linked to the "CAN" Schedule.

The commitment for collaborative planning and monitoring with Big Room was ensured by inclusion of special clause in contractual agreements among the involved stakeholders. The contractual condition helped all stakeholders take the Big Room meetings and LPS seriously. The management of each of the representatives from owner, general contractor, PMC, and sub-contractor ensured that the Last Planners attended the meetings. And once the Last Planners understood the intent of the meetings and the ambience setup in the Big Room and the Last Planner System ${ }^{\mathrm{TM}}$, their willingness to participate increased within the first couple of weeks.

But what was observed after a few weeks into the process is that even percentage planned complete (PPC), at times, showed high values but the milestones were not achieved. It caused lack of faith in Big Room technique because overall project delays 
were clearly visible while PPC had higher values, above 80 percent. One of the reasons assessed was that this was a complex project and could not be managed as a single project. The project was divided into 9 reasonably independent zones such as Tower 1 , Tower 2 , common area utilities, external infrastructure etc. for better planning and coordination. In addition to the Last Planners, the team proposed a governance structure that allows for decision making to be decentralized and ensured that critical decisions were escalated as needed within the look-ahead window. Each team representing a zone would independently maintain their own weekly planning sessions and daily huddles. However, all of the information across all zones were put in the same Big Room so that any crosscutting information across zones could also be discussed. Thus, an ecosystem enabling reliable promise was created.

At this juncture, the developed BREI was launched on this project and monitored on a weekly basis. The BREI helped in identifying and addressing implementation gaps in LPS. Lean coach and lean mentors addressed these gaps and weekly PPC average scores started stabilizing and resulted in improved BREI scores. The implementation of BREI brought certainty about weakness or gaps in holistic implementation. Big Room pull planning thus was effective after BREI implementation.

As part of research methodology followed for this study, participants in Big Room meetings were asked to narrate a critical incident that can explain the effectiveness of the Big Room meetings. This resulted in collation of many instances from a variety of disciplines including concreting, HVAC, fabrication etc. One such incidence related to slab cycle is illustrated below.

Based on CPM schedule, the management team expected that the slab cycle in Zone 1 would be 15 days, considering this activity was on the critical path. However, initial discussion with last planners indicated that achieving slab cycle was challenging. The owner's planning and contract administration team stressed that there was no possibility of milestone extension. On the other hand, the contractor was exploring possibility of claims based on design release dates and changes attributable to owner. The distrust between the two parties affected collaborative efforts. The last planners of Zone 1 felt that stricter deadlines are imposed without resolving constraints faced by them and started losing faith in the Big Room meetings and felt deceived owing to lack of power to say "NO". Not surprisingly, the BREI scores for this Zone 1 were low. In order to save the situation, the lean coach facilitated a meeting between the lean core team, owner planning team, and Zone 1 in charge for meaningful interaction. The team analysed the information pertaining to PPC and constraint logs and identified areas of improvements. Constraints of the last planners were resolved. The team identified wastages that could be eliminated for reduction of slab cycle, thus bringing the slab cycle time to a more mutually acceptable 21 days. Owner and shop drawing team accepted the delay of 6 days caused by a complex reinforcement design at elevator shaft; a genuine constraint that took time to resolve. The team considered this improvement as the biggest breakthrough in their zone. The slab cycle became more consistent and reliable, and BREI as well as PPC score improved consistently. The Big Room participants felt that BREI became a trust building mechanisms and helped in undertaking improvements in appropriate areas.

\section{DISCUSSION}

This section discusses the BREI framework and the results of its application in a project. It also discusses the limitation of the research with scope for future research on the same. The authors are aware that the BREI framework attempts to measure collaboration in the 
Big Room, which is a qualitative metric, using quantitative measures. The authors understand and acknowledge that actual weekly BREI value is not a measure of collaboration and trust within the team. As a qualitative measure, the authors conducted a video interview of the project managers and planning engineers of the owner, general contractor, and the PMC. All of them universally acknowledged the impact of Big Room meetings and LPS, but also were happy with the introduction of BREI as a measurable outcome within limitations to the effectiveness of the Big Room meetings. The authors understand and acknowledge that actual weekly BREI value may not be interpreted as an exact measure of collaboration and trust within the team. However, the authors believe that the week-on-week trend is indicative of whether or not the teams are functioning effectively and whether or not trust and collaboration was improving (or not) within the team. That is where the authors believe the value of the framework lies.

One of the limitations of the study is that the framework must be applied to more projects and possibly on a wider range of projects before its effectiveness and robustness can be assessed. The second limitation is the exhaustiveness of the list of parameters and the weightages for each of them. Both of these lead to the future work on BREI. The authors plan to apply this on their next assignment and will report on the learnings if any. The authors are also willing to work with collaborators who want to try the framework on their projects for collaborative learning.

\section{CONCLUSION}

The paper proposes a quantitative framework to assess the effectiveness of collaborative planning in the Big Room. Based on action research, a set of 10 parameters were proposed and consolidated into four categories. Weightages for each of the parameters were jointly arrived at in the context of applying the framework for a commercial real estate project

in India. Feedback from the site indicated that the BREI index provided a guide and a measure to assess effectiveness and the team was happy with its induction. The index is a composite measure of various parameters that can direct attention to finer working of Big Room meetings. The trend analysis of this index over a period of time helped, on one hand, in fine tuning working of Big Room and on the other, afforded confidence to the decision makers about potential improvements. This matrix is very useful especially in case of organizations/teams in an early stage of Big Room adoption. It can be a very useful tool for Lean Coaches worldwide to measure Big Room Effectiveness during the transitional journey of any organization.

The Index weightages and sub categories are changeable to suit individual requirements. Eventually, the authors believe that the relative weightages across the categories will indicate the value each project is trying to get out of the Big Room meetings. The categories and the sub categories may also be changed to suit the requirements of any organisation. The understanding of reliable promising is often not holistically understood or facilitated at senior/middle levels of project hierarchy and BREI gives a good feedback so that aspiring lean mentors could have tangible records to make team members realize where the efforts for improvement are essential.

\section{REFERENCES}

Ballard, G. 1999. "Improving Work Flow Reliability." Proc. $7^{\text {th }}$ Annual Conference of the International Group for Lean Construction, Berkeley, USA, 275-286. 
Ballard, G., Tommelein, I., Koskela, L., and Howell, G. 2007. "Lean construction tools and techniques." Design and Construction, R. Best, and G. de Valence, eds., Routledge, London, 29.

Costello, P. J. M. (2003). Action Research, Continuum, London.

Daniel, E. I. 2017. Exploratory study into the use of Last Planner ${ }^{\circledR}$ System and collaborative planning for construction process improvement. Doctor of Philosophy, Nottingham Trent University, Nottingham.

Hamzeh, F., Ballard, G., and Tommelein, I. D. 2012. "Rethinking Lookahead Planning to Optimize Construction Workflow." Lean Construction Journal, 15-34.

Hill, K., and Fauchier, D. 2016. "The Mindset of an Effective Big Room." $18^{\text {th }}$ LCI Congress, Lean Construction Institute, Chicago.

Khanzode, A. 2020. "Making the Big Room Better: Using Information Flows To Show Who Matters When And Making Collaboration More Efficient." $<$ https://www.dpr.com/view/making-big-room-better $>$. (May 06, 2020).

Korb, S. 2016. "“Respect for People" and Lean Construction: Has the Boat Been Missed?" Proc. 24th Annual Conference of the International Group for Lean Construction, Boston, USA.

LCI 2015. "The Mindset of an Effective Big Room." Lean Construction Institute, Inc., Arlington, VA, 1-3.

Majava, J., Haapasalo, H., and Aaltonen, K. 2019. "Elaborating factors affecting visual control in a big room." Construction Innovation, 19(1), 34-47.

Mossman, A. 2015. "Bringing Lean Construction to Life: Developing Leaders, Consultants, Coaches, Facilitators, Trainers \& Instructors." Proc. 23rd Annual Conference of the International Group for Lean Construction, Perth, Australia, 413423.

Priven, V., and Sacks, R. 2015. "Effects of the Last Planner System on Social Networks among Construction Trade Crews." Journal of Construction Engineering and Management, 141(6), 04015006.

Ravi, R., Lædre, O., Fosse, R., Vaidyanathan, K., and Svalestuen, F. 2018. "The Last Planner System: Comparing Indian and Norwegian Approaches." Proc. 26th Annual Conference of the International Group for Lean Construction, Chennai, India, 381391.

Salvatierra, J. L., Funk, R., and Alarcón, L. F. 2016. "Chilean Construction Industry: Workers' Competencies to Sustain Lean Implementations." Proc. 24th Annual Conference of the International Group for Lean Construction, Boston, USA.

Tezel, A., Koskela, L., Tzortzopoulos, P., Talebi, S., and Miron, L. 2018. "Continuous Improvement Cells in the Highways Sector." Proc. 26th Annual Conference of the International Group for Lean Construction, Chennai, India, 691-707.

Viana, D. D., Formoso, C. T., and Isatto, E. L. 2017. "Understanding the theory behind the Last Planner System using the Language-Action Perspective: two case studies." Production Planning \& Control, 28(3), 177-189. 